\title{
Above and beyond: when we ask personal protective equipment to be community protective equipment
}

\author{
Kirsten Koehler $\mathbb{D}^{1} \cdot$ Janice Ruggles ${ }^{2} \cdot$ Ana M. Rule $^{1}$ \\ Keywords Environmental monitoring · Workplace exposures · Inhalation exposure
}

Received: 26 June 2020 / Revised: 6 October 2020 / Accepted: 19 November 2020 / Published online: 12 December 2020

This is a U.S. government work and not under copyright protection in the U.S.; foreign copyright protection may apply 2020

Personal protective equipment (PPE) has gone from occupationally related terminology to everyday household jargon in just a few months during the COVID-19 pandemic. Unfortunately, not everything that we loosely call PPE can be treated equally during this pandemic. In fact, there has been a fair amount of debate and confusion about what can be considered PPE given shortages of appropriate equipment. When making recommendations for PPE use, it is important to remember that in the case of COVID-19, we are seeking to protect both the wearer and those around them in the event of asymptomatic spread. Face coverings that seek to reduce exposures for the wearer and those around them can be called community protective equipment (CPE) $[1,2]$. Surprisingly, few devices can serve as what we propose calling community and personal protective equipment (CPPE), face coverings that can serve to protect the wearer and as source control, ideally reducing particle concentrations in both inhaled and exhaled air by at least 95\%. Reliable information is needed on which types of face coverings (CPE, PPE, and CPPE) are suitable in different environments. This article lays out the features, functionality, and limitations of the different types of face coverings that the general public is encountering, facilitates selection of appropriate coverings, informs policy on recommendations for use in the community, and calls on the need for the introduction of standards for CPPE and guidance for CPE.

$\triangle$ Ana M. Rule

arule1@jhu.edu

1 Department of Environmental Health and Engineering, Johns Hopkins Bloomberg School of Public Health, Baltimore, MD, USA

2 Office of Safety, Health \& Environmental Management, Smithsonian Institution, Washington, DC, USA
Although the term PPE has entered the general public's terminology, there is still substantial uncertainty among the public and some policy makers about how effective masks or face shields are at reducing the spread of COVID-19. Exposure scientists play an important role in promoting sound public health policy related to PPE use and COVID19 , and disseminating this information to the public. At the same time, we must continue to think critically about how the same mask can offer different levels of protection to the wearer and to the community.

PPE is engineered to protect the wearer, hence, personal protective equipment. It was not designed to protect others from exhaled breath. That consideration has generally not been needed until now, when people infected with SARSCOV-2 can spread infection while not exhibiting symptoms [3]. If available equipment is not CPPE, protecting both the wearer and community, the need for additional protective measures like physical distancing and ventilation, must be clearly communicated (Fig. 1) [4]. Furthermore, the use of PPE, CPE, and/or CPPE should always be used as a last resort given its position at the bottom of the hierarchy of controls framework used in occupational health for controlling exposure to hazards [5].

PPE must be specific for its purpose. Different types of respiratory protection are designed in a way that protects wearers from a wide range of aerosol sizes (including viral aerosols), but to be effective, users must be trained and fit tested as appropriate (see OSHA 29CFR1910.134), which poses a problem for its use by the general public. Health care workers need access to PPE to care for infected patients, particularly during aerosol-generating procedures [6]. However, until adequate testing is available to ensure wearers are not asymptomatic carriers, some PPE (as opposed to CPPE) may pose a risk to nearby uninfected staff, clients, or bystanders. Examples of such limitations with current PPE include vented filtering facepiece respirators (FFR), elastomeric respirators, and powered air-purifying respirators 
Fig. 1 CPPE at the intersection between community and personal protective equipment. Image credits: [12-15].

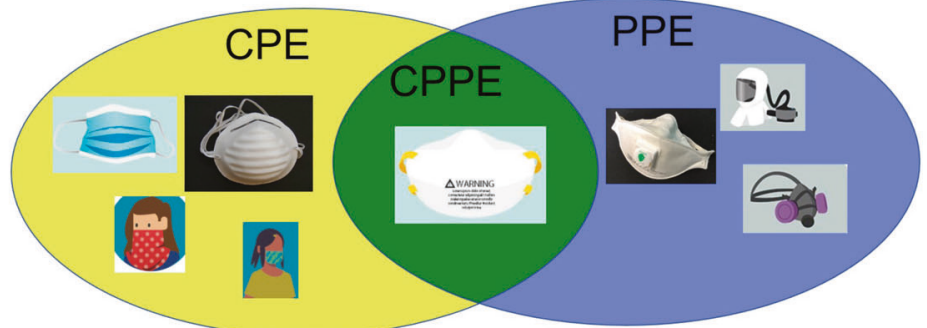

\begin{tabular}{|c|c|c|c|}
\hline & CPE & CPPE & PPE \\
\hline Examples & Surgical, cloth, and dust masks & Unvented FFR (N95 or better) & $\begin{array}{l}\text { Vented FFR, PAPR, elastomeric } \\
\text { respirators }\end{array}$ \\
\hline \multicolumn{4}{|l|}{ Protection for Wearer } \\
\hline Droplets & Provides some protection & At least $95 \%$ removal* & At least $95 \%$ removal \\
\hline Aerosols & Provides very limited protection & At least $95 \%$ removal* & At least $95 \%$ removal \\
\hline \multicolumn{4}{|c|}{ Protection for Community } \\
\hline Droplets & Provides some protection & At least $95 \%$ removal* & $\begin{array}{l}\text { Use with caution because of } \\
\text { unfiltered exhaled breath }\end{array}$ \\
\hline Aerosols & Provides very limited protection & At least $95 \%$ removal* & $\begin{array}{l}\text { Use with caution because of } \\
\text { unfiltered exhaled breath }\end{array}$ \\
\hline Appropriate Use & $\begin{array}{l}\text { For community use while CPPE not } \\
\text { available }\end{array}$ & $\begin{array}{l}\text { Prioritized for medical personnel } \\
\text { during shortages; ultimately for } \\
\text { everyone }\end{array}$ & $\begin{array}{l}\text { Prioritized for medical personnel } \\
\text { during shortages; use with caution } \\
\text { because of unfiltered exhaled breath }\end{array}$ \\
\hline Additional Protections & Maintain social distancing & Training for proper fit* & $\begin{array}{l}\text { Training required; fit testing may be } \\
\text { required; maintain social distancing }\end{array}$ \\
\hline
\end{tabular}

(PAPR), which were being used in health care settings during the worst of the PPE shortage. PAPRs are still being used when staff fails the N95 fit test, and because they are more comfortable. When worn correctly, these three types of respiratory protection provide a minimum $95 \%$ efficiency of particle removal for the wearer of the respirator. However, in each case, unfiltered exhaled air from the wearer escapes the mask or helmet. For example, the exhalation valves in vented FFR, are designed to allow for the passage of exhaled breath into the ambient environment to reduce breathing resistance while adequately protecting the wearer. Vented FFR are not recommended in health care settings, but due to recent shortages, some low resource locations (i.e., countries in Latin America and Africa) are using whatever is available. In absence of shortages, they are also commonly available at hardware stores for the general public. It is not currently known what portion of exhaled droplets (particles with diameter $>5 \mu \mathrm{m}$ ) or aerosols (particles with diameter $<5 \mu \mathrm{m}$ ) escape from these types of PPE, but based on basic aerosol theory, they are not expected to provide adequate protection for nearby people. Because surgical masks and face shields are not suited for protection against viral aerosols, we do not consider them respiratory PPE in the context of COVID-19.

$C P E$ is worn to help reduce the spread of disease and can include surgical, dust, and fabric masks, recommended in light of PPE shortages. CPE masks are intended to help prevent the spread of droplets from speaking, coughing, and sneezing. As exposure scientists, we must clearly communicate the limitations of each to decision makers, including that CPE cannot fully protect the wearer or other individuals around them, particularly from aerosols. Depending on the type of material, the mask design (ear loops vs. straps) and the size of the particles, the particle filtration efficiency can vary widely from $<20 \%$ for some fabrics [7] to $95 \%$ for some surgical masks $[8,9]$. However, it is important to remember that these masks do not provide a seal around the face. The result is that particles travel around the sides of the mask, making the total protection lower than measured for the material itself [9]. Furthermore, cloth masks featuring exhalation valves are now being introduced into the market, which may reduce their effectiveness in reducing concentrations of exhaled droplets and aerosols. Additionally, dust masks intended for protection against nuisance dust, were not designed to protect against infection. Concerningly, they can be mistaken for N95s because of their similar shape.

There is a growing understanding that although fabric masks provide some reduction in the spread of droplets, their efficiency in removing aerosols may be minimal. Until the relative role of droplet vs. aerosol transmission is better understood for SARS-COV-2, exposure scientists must continue to make it clear that fabric masks are not PPE and social distancing must be paired with their use. Recognizing that face masks are uncomfortable to wear and can reduce communication ability in educational settings and for hard of hearing people, there is growing interest in the ability of face shields to serve as CPE. Face shields are often used in health care settings as PPE to protect the eyes against splashes (often in conjunction with surgical masks or FFR), but these shields fit very loosely around the face. Existing data shows that face shields may provide some protection for the wearer against droplets (up to $40 \%$ for someone coughing in close proximity) [10], but they likely provide minimal protection against inhalation and exhalation of aerosols, though confirmatory data is lacking. We caution the recommendation of face shields, even as CPE, until 
more data are available showing efficacy at particle removal or eye protection under normal breathing conditions. Face coverings with clear windows that allow full view of the wearer's mouth have been introduced to the market. These would be preferable to a face shield. Guidance on appropriate materials are needed to help the public and policy makers select the best face covering for their use.

$C P P E$, needed for the current pandemic, seems to be limited to unvented FFR (Fig. 1). However, caution should be exercised as there is little data on their effectiveness as source control to prevent spread of infectious aerosols [11], particularly on those using them without a fit test or when speaking, coughing, or sneezing [4]. Furthermore, the resistance against breathing through FFRs may be intolerable for some people. Thus, their role in preventing the spread of COVID-19 should not be overstated.

Standards for fabrication of CPPE and appropriate testing procedures should be created to establish minimum levels of filtration for acceptable face coverings (ideally at least 95\%). This data should consider both the removal efficiency for inhaled aerosols (typically dry, with a smaller size distribution) and exhaled aerosols (wet aerosols with a larger size distribution) for both optimal and typical use. Standards should also address the physiologic differences between adults and children, who have not typically been considered in the development of PPE.

More data is needed regarding particle removal efficiency of different face coverings to inform policies for reopening schools, businesses, and recreational activities. Furthermore, new types of face coverings may be needed to meet the ongoing needs during the COVID-19 crisis and to prepare for future epidemics. When designing masks, their use as CPPE should be considered and rigorous aerosol science should be used when testing new materials and masks. Development of standards for the manufacture and testing of items that may be considered acceptable as CPPE is also warranted to ensure that suitable products are available.

Acknowledgements This publication was supported by the Grant or Cooperative Agreement Number T42OH008428, funded by the Centers for Disease Control and Prevention. Its contents are solely the responsibility of the authors and do not necessarily represent the official views of the Centers for Disease Control and Prevention or the Department of Health and Human Services.
Conflict of interest The authors declare that they have no conflict of interest.

Publisher's note Springer Nature remains neutral with regard to jurisdictional claims in published maps and institutional affiliations.

\section{References}

1. University C. COVID-19 hierarchy of controls. 2020. https://ehs. cornell.edu/campus-health-safety/occupational-health/covid-19/ covid-19-hierarchy-controls.

2. UNC. COVID-19. 2020. https://ehs.unc.edu/infectious-diseases/ coronavirus/.

3. Oran DP, Topol EJ. Prevalence of asymptomatic SARS-CoV-2 infection. Ann Intern Med. 2020;173:362-7.

4. Brosseau L, Sietsema M. COMMENTARY: masks-for-all for COVID-19 not based on sound data. 2020. https://www.cidrap. umn.edu/news-perspective/2020/04/commentary-masks-all-covid19-not-based-sound-data.

5. CDC. Hierarchy of controls. 2015. https://www.cdc.gov/niosh/ topics/hierarchy/default.html.

6. Tran K, Cimon K, Severn M, Pessoa-Silva CL, Conly J. Aerosol generating procedures and risk of transmission of acute respiratory infections to healthcare workers: a systematic review. PLOS ONE. 2012;7:e35797.

7. Rengasamy S, Eimer B, Shaffer RE. Simple respiratory protection-evaluation of the filtration performance of cloth masks and common fabric materials against $20-1000 \mathrm{~nm}$ size particles. Ann Occup Hyg. 2010;54:789-98.

8. Oberg T, Brosseau LM. Surgical mask filter and fit performance. Am J Infect Control. 2008;36:276-82.

9. Sickbert-Bennett EE, Samet JM, Clapp PW, Chen H, Berntsen J, Zeman KL, et al. Filtration efficiency of hospital face mask alternatives available for use during the COVID-19 pandemic. JAMA Intern Med. 2020;180:1607-1612. https://doi.org/10.1001/ jamainternmed.2020.4221

10. Lindsley WG, Noti JD, Blachere FM, Szalajda JV, Beezhold DH. Efficacy of face shields against cough aerosol droplets from a cough simulator. J Occup Environ Hyg. 2014;11:509-18.

11. Tang JW, Liebner TJ, Craven BA, Settles GS. A schlieren optical study of the human cough with and without wearing masks for aerosol infection control. J R Soc Interface. 2009;6:S727-36.

12. CDC. Elastomeric respirators: strategies during conventional and surge demand situations. 2020. https://www.cdc.gov/coronavirus/ 2019-ncov/hcp/elastomeric-respirators-strategy/index.html.

13. CDC. Understanding the difference. https://www.cdc.gov/niosh/ nppt1/images/100years/UnderstandDifference3.jpg. Accessed 2020.

14. CDC. Important information about your cloth face coverings. 2020. https://www.cdc.gov/coronavirus/2019-ncov/downloads/cloth-facecoverings-information.pdf.

15. Wikipedia. Dust mask. 2020. https://en.wikipedia.org/wiki/Dust_ mask. 